\title{
Automated Fertilizer Mixer System for Fertigation Farming
}

\author{
M.F.Saaid, MK Nordin, Ahmad Ihsan Mohd Yassin, and Nooritawati Md Tahir
}

\begin{abstract}
This paper describes the automatic fertilizer mixer for fertigation farming system using microcontroller. The purpose of this project is to study the effectiveness of the system in mixing the raw ingredients of fertilizers into either set $A$ or set $B$ fertilizers using a low-cost system. An Arduino microcontroller, LCD, keypad, and motors used to operate the system for separating the raw ingredients and mixing it to form the result of fertilizer mixtures. The final mixture results referred to as the amount of the raw ingredients recorded for a specific level of water by adhering to the given formula. After several experiments conducted, this technique proven to be an effective way of separating and mixing the fertilizers mixtures. The mixture ingredients were successfully mixed, and the given formula was strictly followed. The combination had been mixed with a low weight percentage of error by separating it using this developed system. The overall functions of the system have met the objectives by successfully combining the mixture
\end{abstract}

Index Terms - fertigation system; fertilizer mixer system; micro-controller; automation system

\section{INTRODUCTION}

$\mathrm{W}^{\mathrm{n}}$ ITHIN the framework of agriculture, fertigation market has shown unprecedented growth in terms of its widespread use and technological advancement. In as much, agriculture will continue to play an essential role in the economic growth and poverty alleviation in developing countries in this era of economic liberalization and globalization [1]. The agriculture sector can also improve the economy of developing countries such as Nigeria and others. Their economy and combined with a significant effort to reduce food imports and to increase food production within their own country, Nigeria can see a timely turn around in their investment [2].

Fertigation is one of the agriculture methods of farming techniques. This technique is known as one of the best ways to utilize because of its high productivity and efficiency in using resources [3]. It is because the old methods are not timeefficient in supplying the nutrients needed by the plants,

This manuscript is submitted on 16th October 2020 and accepted on 9th March 2021.

M.F.Saaid, MK Nordin, A.I.M Yassin and Nooritawati Md Tahir are with Faculty of Electrical Engineering, Universiti Teknologi MARA (UiTM) Shah Alam, 40450 Selangor, Malaysia (email: mfarids@uitm.edu.my).

1985-5389/C 2021 The Authors. Published by UiTM Press. This is an open access article under the CC BY-NC-ND license (http://creativecommons.org/ licenses/by-nc-nd/4.0/). as human are not robots that can do things on the exact time daily. There is going to be a delay within the working time. Not only that, but human also tends to not accurately use the resources given to them because there is the limitation of manual calculation of the number of resources to be used [4]. By using the system, the number of resources would be calculated accurately to prevent the overuse of the resources.

In Malaysia, peppers are the common plants that use the fertigation method to grow because peppers need maximum care in fertilization and watering. Levels of fertigation and crop coefficient can affect plant growth, dry matter partitioning and the yield of chillies. The problem of the current system is that the system is not fully efficient in supplying the correct amount of fertilizer and the volume of water for the plants based on their optimum requirements [5]. So, a system that can properly mix the ingredients needs to be developed to overcome the problem of incorrect fertilizer amount used for the plants, as in the system will accurately separate and mix the fertilizer.

There are opportunities for improvement in this sector, which based on advanced technology nowadays [6]. Using microcontrollers and sensors are the best solution to upgrade the current system to be a more advanced system [7, 8]. Advanced technology will increase the productivity and efficiency of the system. It will have a more significant impact of drip irrigation and fertigation on growth, yield, quality and economic returns in different vegetable crops [9].

Economy growth in a country depends on how active the industries' business so that the development and improvement of the economy will be slightly faster and better if the sectors are actively running $[10,11]$. There are many types of industries business, such as manufacturing, agriculture, transportation, and construction. Agriculture is known as a profitable business with the impressive impact of the sector on countries like India [12]. Agriculture has two parts of farming which are arable farming and pastoral farming. Arable farming where farmers plough the land, sow seeds and grow plants to harvest. Stuff like vegetables and so on is involving in arable agriculture. Pastoral farming is where an animal is involved. Animals such as cattle, chicken and sheep are in rural agriculture.

Vegetable farming used because the process of this farming method is more straightforward. Handling vegetables is cheaper than animal by comparing the business capital value. In agriculture, there are many methods to be done to grow crops. Three ways can be found such as irrigation system, fertigation 
system and hydroponic. Fertigation system is very suitable for vegetable planting as fertigation is the injection of fertilizers, soil amendments, and other water-soluble products into an irrigation system [13].

Fertigation is related to chemigation, the injection of chemicals into an irrigation system. The benefits of fertigation methods over conventional or drop-fertilizing methods include three common factors. The factor is; increased nutrient absorption by plants [14], reduction of fertilizer, chemicals, and water needed; and removal of soil erosion issues as the nutrients pumped through the water drip system. As the pepper tree is susceptible and the nutrition of the vegetables need to handle extra care, so this fertigation system is very suitable. The effect of the fertigation system in the economy is in positive feedback [15].

The main item of the fertigation system is fertilizer [16]. The fertilizer needs to be in an accurate value base on the formula given before the system can distribute it to the plant as the fertilizer need to be full of nutrient and accurately for the plant to maximize its growth to the max potential for more crops [17]. The effect of the fertilizer is a different base on the value of nutrient being mixed in the mixture [18]. The more accurate of he nutrient needed by the plant being distribute will make the plant boost the growth at the max potential [19].

In a basic fertigation technique, there are two sets types of fertilizer. Each of the fertilizer set contains difference nutrients that need to be a mix. The first fertilizer sets contain four ingredients which are Calcium Nitrate, Potassium Nitrate, Iron, and ammonium nitrate. Calcium, iron and potassium slightly give the effect of growth on the plants [20]. Second sets contained potassium nitrate, Mono-potassium hydrogen phosphate, magnesium sulphate, manganese sulphate, boron, zinc sulphate, copper sulphate, and sodium. The ingredients are very suitable for maximizing the growth of the plant, and the effect of the nutrients it can yield more crops [21].

In a conventional method, all this set of fertilizer needs to mix manually, which consume times and energy. A person needs to start the process by weighing the raw materials base on the formula precisely and consume so much time. After the weighing process, the user needs to add the raw materials

Power in ztogether into the water and then stir it manually to mixing the compound on the raw materials for each set. Shah Abd Hafiz Zainal Abidin et al. [22] proposed web-based monitoring for an automated fertigation system. The data from the fertigation system was displayed in the web-GUI for monitoring purpose. The user easily managed the fertigation system using mobile devices. A researcher [23], proposed a design of an automated fertigation system using IoT. The design contained Arduino, soil moisture sensor, $\mathrm{pH}$ sensor, EC sensor, XBee, solenoid valves and relay. The controlled fertilizer, $\mathrm{pH}$ and EC. IoT technology enables the user to monitor and control the system for some distance. However, the research was not emphasized the amount of fertilizer to be implemented in the system. Research is done by [24] on automated fertigation system for efficient utilization of fertilizer and water. The system integrated with a WIFI module to serve the user an option for transmitting the data using the internet. The system controlled a fertilizer mixing (NPK) and the delivery method but need some study about the effectiveness and the precision of the proposed system. By taking a similar principle and drawbacks, this paper was proposed the automatic system of mixing the fertilizer to solve the problem of consuming time and energy.

Automatic fertilizer mixture system used to reduce the time taken and the usage of human energy. This developed system can be separated into three stages. The first process is placing the raw materials in a starter tank, and then the user needs to store specific data. The last process is the automatic process which mixing and stirring the mixture. The process automatically controlled by a microcontroller without a complicated process to handle. This system was able to reduce the overhead cost for the owner, thus increasing the saving of the capital.

\section{RESEARCH METHOD}

This section will discuss in detail the experimental and analysis method that has been developed in measuring the $\mathrm{pH}$ level.

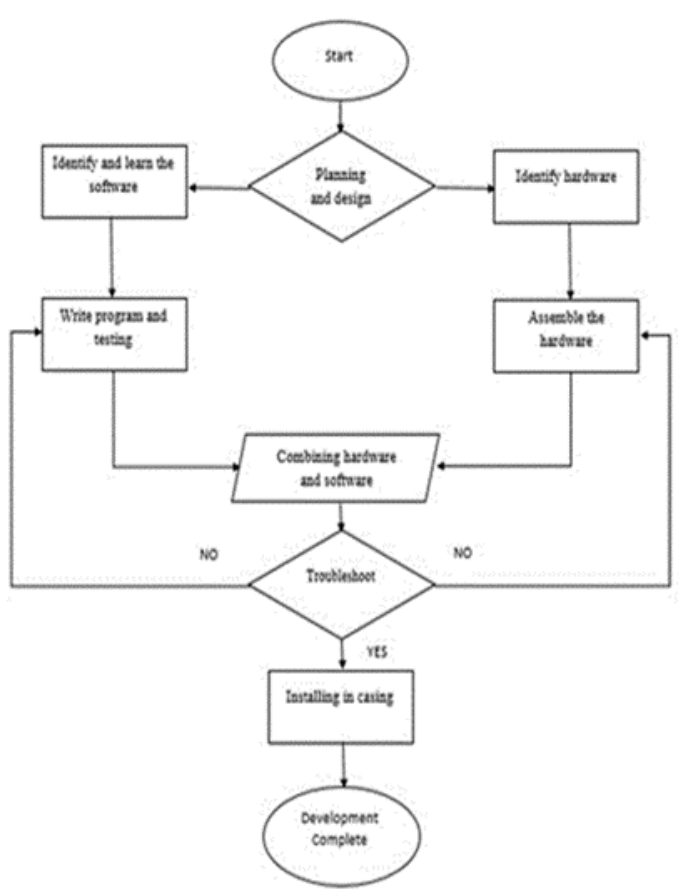

Fig. 1. Flowchart for a research method

Figure 1 shows the flowchart of the project and how it will be implemented. Hardware design developed to build a system so that it can be used for interfacing between the user and the system. In contrast, the software design consists of programs to control the whole process of microcontroller regarded analysis and communication between devices.

In general, this project will be implemented in several stages. The first stage is to conduct a preliminary study on the relevant subjects regarding the project, such as telemetry system fundamentals, knowledge of C Language and compiler, circuit design, and etc. Upon completing this stage, the second stage is interfacing the hardware. Circuits were designed and simulated 
by using Arduino-IDE to ensure that they are all free from error. The next step is to develop the programming using Arduino Compiler.

Then the integrations for both software and hardware was carried out before troubleshooting the whole system. Simulation by using PROTEUS-ISIS was carried out before implementing the hardware. Debugging work was executed to identify and solve the problem. Then, the final stage is to embed the software (programmed) into the Arduino microcontroller.

\section{A. System development}

The programming development for this system divided into two parts. The first part is the programming language used to control the microcontroller for the input section, which contains a keypad. The keypad is the input device for the user to key in the desired input system to perform the task based on the entered value.

The second part of the software is the output process. The output process is when the microcontroller performs the task from the input signal the user has keyed in. The output will follow the instruction and the value of the given input. The programming language that will be used is the $\mathrm{C}$ or $\mathrm{C}++$ language.

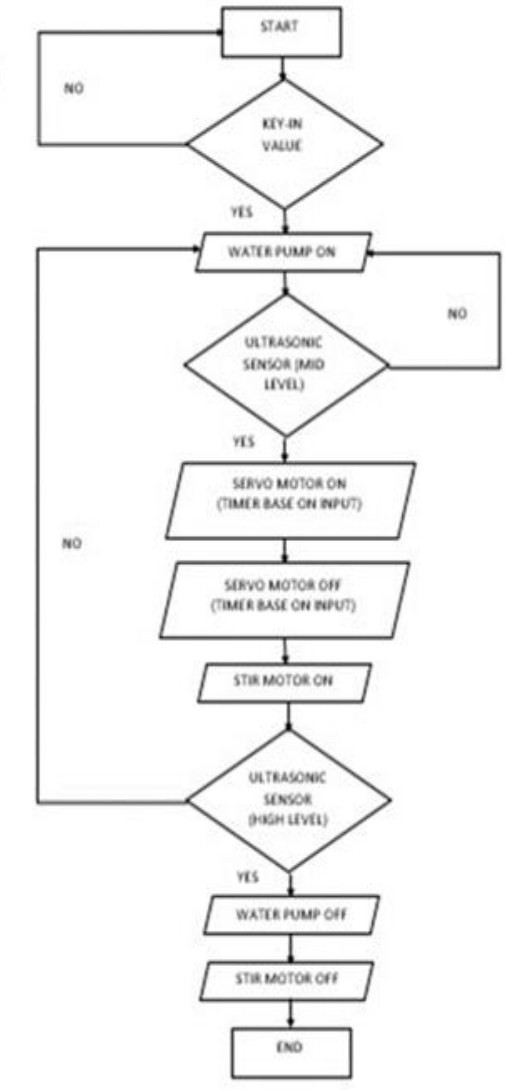

Fig. 2. Automated fertilizer mixer system flowchart

Figure 2 shows the flowchart of the hardware development system. The hardware of the system consists of two parts; the automation part and the controller part. In the automation part, the signal sent to the output based on the action triggered by the input (keypad, timer and sensor) as shown in Figure 3. After the user had entered the required delay time, the water pump would be turned on. The water pump will fill the main tank with water until the ultrasonic detect the water to stop the process. The servo motor and stir motor will be turned on after the detection of mid-level water by the sensor. The servo motor would operate based on the timer that set by earlier by the user. The user will specify how long the servo motor will be on based on the weight of materials needed in gram. The programmer had programmed the timer-weight ratio based on an experiment conducted to obtain the exact percentage to satisfy the result.

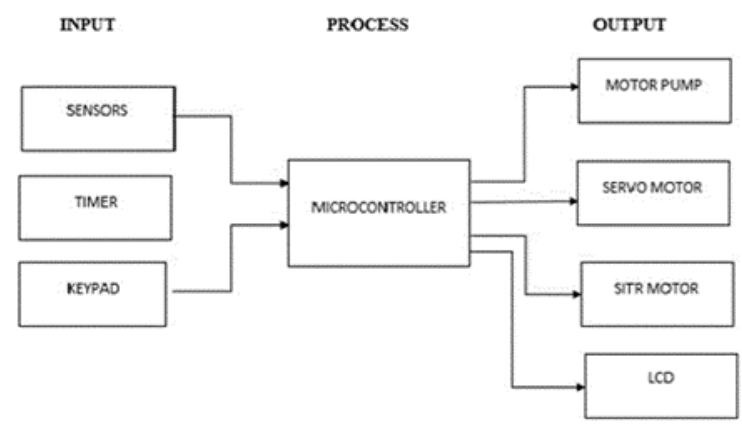

Fig. 3. Automated fertilizer mixer system block diagram

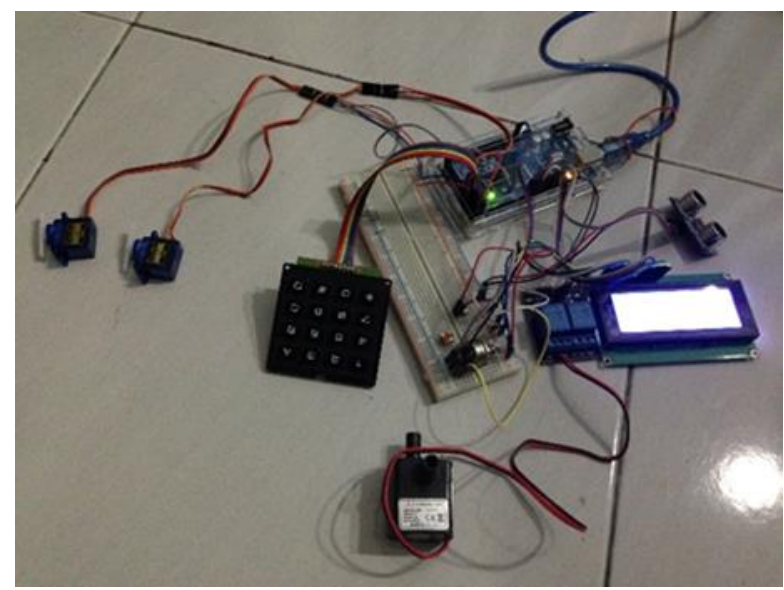

Fig. 4. Input, output, and microcontroller integration

Figure 4 shows the integration between inputs, outputs, and microcontroller. This hardware used to configure to achieve the desired results. There is three steps mode to run this system which are standby mode, input mode and process mode. The standby mode is when the system started and change into standby mode before the input process started. The output process triggered after the input process completed. The Arduino will send all the signals to the hardware to perform the tasks based on the coding.

The keypad used to select and control the input which was being displayed by the LCD. Every button on the keypad has its function except for button 'B" which had been set by programming. Buttons' $1-9$ ' are used to key in the value of the input. Button ' $*$ ' acts as an upward key where the cursor displayed on the LCD will move upward by pressing the '*' 
button. Button' \#' is the downward key where the function is similar to the '*' button but in the opposite way of movement. Button ' $\mathrm{C}$ ' acts as a SELECT button when the user wants to select a menu in the LCD, and button ' $\mathrm{C}$ ' will be pressed. Button ' $\mathrm{D}$ ' is our BACK button; everything that has been chosen can be undone by pressing the 'D' button. Finally, the button 'A' is for 'ENTER' function. The system will start after the user press button 'A'.

The ultrasonic sensor will detect the level of water in the main tank. There are two input signals transmitted using this sensor. The first input is mid-level water, and the second is when the water reaches the maximum level of the main tank. The ultrasonic sensor was preferred because the sensor is more sensitive in detecting particles.

Servo motors used to apply the exact value of the ingredients. The LCD will display the motor status in real-time. The servo motors activated after the sensors detected the mid-level of water in the main tank. After the servo is at open condition, there will be a delay before the servo recloses based on the input value. At this position, servo motors used as the separator of the mixture. A $12 \mathrm{~V}$ water pump used in this project because of the only $12 \mathrm{~V}$ needed for the small-scale system. The water pump will start when the keypad button 'A' pressed.

\section{B. Experiment setup}

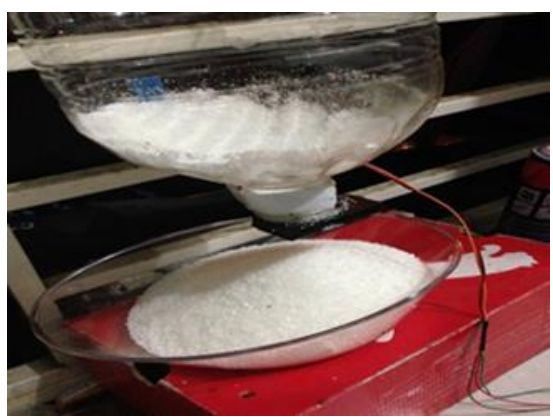

Fig. 5. Input, output, and microcontroller integration

Figure 5 shows the servo motor was attached to the secondary tank. The servo motor will open the tank to let the ingredients flow through it. The delay of the servo motor to close back the tank depends on the input value that was set by the user. The raw ingredients were measured using the scale meter, which was extremely accurate in scaling the small amount of mass after the servo motor is open.

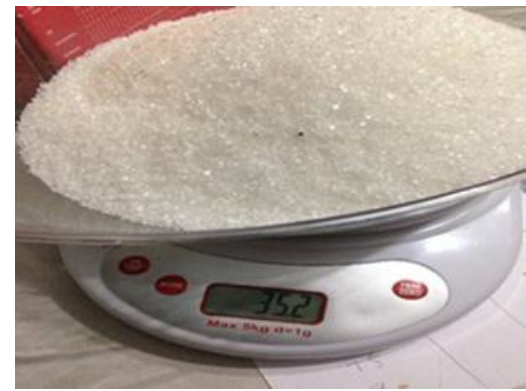

Fig. 6. Scale meter for weight measurement
Figure 6 shows the scale meter used to measure the result of the experiment. The ingredients scaled by the meter. The mass of the item depended on how long the tank was being open. The objective of this experiment was to measure the delay needed to be set on the system to get the desired weight of the ingredients in grams. This scale used to validate the results. The results of servo motor time versus output weight recorded in Table 1. The necessary amount of the water used in this experiment fixed at $15 \mathrm{~L}$, and two sets for mixed fertilizer combination set as below:

Setup 1: Set A fertilizer formula

- Ammonium nitrate - 120gram

- Calcium nitrate - 950gram

Setup 2: Set B fertilizer formula

- Potassium nitrate - 200gram

- Ferrum - 150gram

\section{EXPERIMENTAL RESULTS AND ANALYSIS}

In this section, all the results attained based on the four experimental conducted are reported and discussed.

Setup 1: Set A fertilizer formula

\begin{tabular}{ccccc}
\hline \hline \multirow{2}{*}{ No. } & $\begin{array}{c}\text { Servo } \\
\text { execution } \\
\text { time }(\mathrm{s})\end{array}$ & $1^{\text {st }}$ reading & $\begin{array}{c}2^{\text {nd }} \\
\text { reading }\end{array}$ & Average \\
\cline { 3 - 5 } 1 & 0.5 & 12 & 11 & $\mathbf{3 2}$ \\
\hline 2 & 1.0 & 23 & 25 & $\mathbf{5 0}$ \\
\hline 3 & 1.5 & 34 & 45 & $\mathbf{9 1}$ \\
\hline 4 & 2.0 & 56 & 62 & $\mathbf{1 2 2}$ \\
\hline 5 & 2.5 & 72 & 83 & $\mathbf{1 4 0}$ \\
\hline 6 & 3.0 & 91 & 97 & $\mathbf{1 5 8}$ \\
\hline 7 & 3.5 & 139 & 152 & $\mathbf{1 5 9}$ \\
\hline 8 & 4.0 & 178 & 182 & $\mathbf{2 2 0}$ \\
\hline 9 & 4.5 & 210 & 203 & $\mathbf{2 9 1}$ \\
\hline 10 & 5.0 & 232 & 223 & $\mathbf{3 5 7}$ \\
\hline \hline
\end{tabular}

SERVo Motor EXECUTION TIME VERSUS AMMONIUM NitRATE AND CALCIUM NITRATE OUTPUT WEIGHT

Table I shows the results of the servo motor time versus output weight for the two items, which were ammonium nitrate and calcium nitrate. It is because the error for the materials to go through the tank into the main tank is different for each process. The experiment was conducted for six times with the same value to obtain the average result. This set of data was important as a guide to set the servo motor delay time. From the table, if the user wants the value of the ingredients to be 150 grams, the delay that should be used is between 2.5 seconds and 3.0 seconds. For the formula given, the ammonium nitrate is 120 gram, and calcium nitrate is 950 gram for $15 \mathrm{~L}$ of water, so the delay for 120 grams should be 2.0 seconds and for 900 gram is between 9.5 and 10.0 seconds. 
Setup 2: Set B fertilizer formula

TABLE II

SERvo Motor EXeCution Time Versus Potassium NitRate AND FerRum OUTPUT WEIGHT

\begin{tabular}{ccccc}
\hline \hline \multirow{2}{*}{ No. } & \multirow{2}{*}{$\begin{array}{c}\text { Servo } \\
\text { execution } \\
\text { time }(\mathrm{s})\end{array}$} & $1^{\text {st }}$ reading & $\begin{array}{c}2^{\text {nd }} \\
\text { reading }\end{array}$ & Average \\
\cline { 3 - 5 } & 0.5 & 30 & 34 & 31 \\
\hline 2 & 1.0 & 48 & 52 & 49 \\
\hline 3 & 1.5 & 94 & 88 & 92 \\
\hline 4 & 2.0 & 126 & 118 & 123 \\
\hline 5 & 2.5 & 148 & 132 & 143 \\
\hline 6 & 3.0 & 154 & 162 & 157 \\
\hline 7 & 3.5 & 160 & 158 & 159 \\
\hline 8 & 4.0 & 224 & 215 & 221 \\
\hline 9 & 4.5 & 287 & 294 & 289 \\
\hline 10 & 5.0 & 361 & 353 & 358 \\
\hline \hline
\end{tabular}

Table II shows the results of servo motor time versus the output weight of the ingredients. The experiment was conducted for three times to obtain the average value. The percentage of error can be minimized if the experiment runs for multiple times as the value of the average will be better and more accurate. From the formula given for $15 \mathrm{~L}$ of water, required Potassium Nitrate is 200 gram and Ferrum is 15 grams. From the table, to get 15 grams of weight, the time delay should be between 0.5 seconds and 1.0 seconds. For the Potassium Nitrate, 200gram needs around 4.5 seconds and 5.0 seconds of delay to get the specific weight.

The experiments were conducted separately because of the different types of particle for each ingredient. These experiments were only done for set A because set B also contains the same type of particles such as powder and small pellets and have no significant difference in weight. The two experiments conducted as difference particles have a difference in weight per particle. It is not recommended to take the same particle results to be used for other particles as there are differences in the values. The experiment conducted first, and the results obtained before the powder particles experiment.

From the results shown in the tables, there are differences in the value of powder and pellets weight per delay recorded. The amount of the output slightly differed from the formula, because of the percentage of error of the system. To obtain the accurate values of the weight, we need to upgrade the hardware and conduct more experiments per time delay.

\section{CONCLUSION}

In conclusion, the study of automatic fertilizers mixture successfully developed. The results successfully showed that the system could successfully separate the ingredients according to the given formula and mix it to become sets of fertilizers that were ready to be used. Moreover, the project successfully followed the objectives, which was to develop a low-cost system using useful hardware. Then, the percentage of output error has been minimized to obtain the accurate value for the range of the weight per delay. Also, the system could help upgrade the manual system and would be able to assist the agricultural sector to be more technologically advanced. It can also help in reducing the cost of human power and time consumed and even help in increasing the production of the crops. In a nutshell, this automated fertilizer mixer system able to assist the farmers in their farming process by making the tasks more accurate.

\section{ACKNOWLEDGEMENT}

The authors would like to thank the Faculty of Electrical Engineering, UiTM Shah Alam, Selangor for providing the facilities to conduct this research.

\section{REFERENCES}

O. P. Oluwatoyese and S. D. Applanaidu, "Effect of agricultural sector determinants on economic growth," Handb. Emerg. Trends Sci. Res., pp. 236-242, 2014.

O. Omorogiuwa, J. Zivkovic, and F. Ademoh, "the Role of Agriculture in the Economic Development of Nigeria," Eur. Sci. J., vol. 10, no. 4, pp. 1857-7881, 2014.

Akshay Y. Kachor, Ketaki Ghodinde, "Design of microcontroller based agribot for fertigation and plantation," 2019 International Conference on Intelligent Computing and Control Systems (ICCS), pp. 1215-1219, 2019.

Karl-Johan Bergstrand , Klara Löfkvist \& Håkan Asp, "Dynamics of nutrient availability in tomato production with organic fertilizers," Biological Agriculture \& Horticulture., pp. 200-212, 2020.

A. R. A'fifah et al., "Optimum fertigation requirement and crop coefficients of chilli (Capsicum annuum) grown in soilless medium in the tropic climate," Int. J. Agric. Biol., vol. 17, no. 1, pp. 80-88, 2015.

Rabaia, M.K.H.a, Abdelkareem, M.A., Sayed, E.T., Elsaid, K., Chae, K.-J., Wilberforce, T., Olabi, A.G., "Environmental impacts of solar energy systems: A review," Science of the Total Environment, pp. 1-19, 2021.

Ofoegbu Edward O.1and Ogunmakinde Olabode E, "A Microcontroller Based Building Automation System for real-time Sensing and Control," International Journal of Innovation and Scientific Research vol. 2, no. 2, pp. 275-280, 2014.

Saaid, M.F., Yassin, A.I.M., Tahir, N.M., "Automated monitoring and controlling $\mathrm{pH}$ levels for hydroponics cultivation technique," Indonesian Journal of Electrical Engineering and Computer Science," pp. 1236-1243, 2020.

A. Kritikos, "Entrepreneurs and their impact on jobs and economic

growth," IZA World Labor, no. May, pp. 1-10, 2014.
S. Pramanik, S. K. Tripathi, R. Ray, and H. Banerjee, "Economic Evaluation of Drip-fertigation System in Banana cv. Martaman (AAB, Silk) Cultivation in New Alluvium Zone of West Bengal," Agric. Econ. Res. Rev., vol. 27, no. 1, p. 103, 2014.

Lukas Hardta, John Barretta, Peter G. Taylora, Timothy J. Foxon, "What structural change is needed for a post-growth economy: A framework of analysis and empirical evidence", Ecological Economics, vol 179, pp. 1-13, 2021.

M. Janmohammadi, Z. Sufi-Mahmoudi, A. Ahadnezhad, S. Yousefzadeh, and N. Sabaghnia, "Influence of chemical and organic fertilizer on growth, yield and essential oil of dragonhead (Dracocephalum moldavica L.) plant," Acta Agric. Slov., vol. 103, no. 1, pp. 73-81, 2014.

O. Ng'etich, O. A. Niyokuri, J. Rono, A. Fashaho, and J. Ogweno, Effect of different rates of nitrogen fertilizer on the growth and yield of zucchini (Cucurbita pepo cv. Diamant L.) Hybrid F1 in Rwandan high altitude zone," Int. J. Agric. Crop Sci., vol. 5, no. 1, pp. 54-62, 2013. 
[14] G. Peyvast, J. A. Olfati, P. Ramezani-Kharazi, and S. KamariShahmaleki, "Uptake of calcium nitrate and potassium phosphate from foliar fertilization by tomato," J. Hortic. For., vol. 1, no. 1, pp. 7-13, 2009.

[15] H. Aktaş, K. Abak, L. Öztürk, and I. Çakmak, "The effect of zinc on growth and shoot concentrations of sodium and potassium in pepper plants under salinity stress," Turkish J. Agric. For., vol. 30, no. 6, pp. 407-412, 2006.

[16] R. Kabir, S. Yeasmin, A. K. M. Mominul Islam, and M. A. Rahman Sarkar, "Effect of phosphorus, calcium and boron on the growth and yield of groundnut (Arachis hypogea L.)," Int. J. Bio-Science BioTechnology, vol. 5, no. 3, pp. 51-60, 2013.

[17] B. Kaur and D. Kumar, "Development of Automated Nutrients Composition Control," Int. J. Comput. Sci. Eng. Appl., vol. 3, no. 3, pp. 67-78, 2013.

[18] G. Schiefer, "New technologies and their impact on agriculture, environment and the food industry," EFITA 2003 Conf., no. July, pp. 1-8, 2003.

[19] G. Schiefer, "Effects of vermicompost placement on nutrient use efficiency and yield of tomato (Lycopersicum esculentum)," Biological Agriculture \& Horticulture, pp. 44-52, 2020.

[20] OECD, "Adoption of Technologies for Sustainable Farming Systems," Wageningen Work. Proc., p. 149, 2001.

[21] I. Adofu, S. O. Shaibu, and S. Yakubu, "the Economic Impact of Improved Agricultural Technology on Cassava Productivity in Kogi State of Nigeria," Int. J. Food Agric. Econ., vol. 1, no. 1, pp. 63-74, 2013.

[22] S. A. H. Z. Abidin and S. N. Ibrahim, "Web-based monitoring of an automated fertigation system: An IoT application," in 2015 IEEE 12th Malaysia International Conference on Communications (MICC), 2015, pp. 1-5.

[23] O. M. E. Ahmed, A. A. Osman, and S. D. Awadalkarim, "A Design of an Automated Fertigation System Using IoT," in 2018 International Conference on Computer, Control, Electrical, and Electronics Engineering (ICCCEEE), 2018, pp. 1-5.

[24] C. Joseph, I. Thirunavuakkarasu, A. Bhaskar, and A. Penujuru, "Automated fertigation system for efficient utilization of fertilizer and water," in 2017 9th International Conference on Information Technology and Electrical Engineering (ICITEE), 2017, pp. 1-6. 